\title{
Kinesin family member 11 contributes to the progression and prognosis of human breast cancer
}

\author{
YUAN-YUAN PEI, GAO-CHI LI, JIAN RAN and FENG-XIANG WEI
}

\begin{abstract}
Shenzhen Longgang Maternal and Child Health Hospital Centralab, Shenzhen, Guangdong 518172, P.R. China
\end{abstract}
Received November 7, 2015; Accepted June 2, 2017

DOI: 10.3892/ol.2017.7053

\begin{abstract}
The present study aimed to clarify the association between kinesin family member 11 (KIF11) and human breast cancer, and the effect of KIF11 on breast cancer cell progression. Western blot analysis, reverse transcription-quantitative polymerase chain reaction (RT-qPCR) analysis, retroviral infection, immunohistochemistry staining, MTT assay, anchorage-independent growth ability assay and tumorigenicity assay were all used in the present study. Western blot and RT-qPCR analysis revealed that the expression of KIF11 was markedly increased in malignant cells compared with that in non-tumorous cells at the mRNA and protein level. Immunohistochemical analysis revealed that KIF11 expression was upregulated in 256/268 (95.8\%) paraffin-embedded archival breast cancer biopsies. Statistical analysis demonstrated a significant association between the upregulation of KIF11 expression and the progression of breast cancer. Multivariate analysis revealed that KIF11 upregulation represents an independent prognostic indicator for the survival of patients with breast cancer. Tumorigenicity experiments were further used to evaluate the effect of KIF11 in non-obese diabetic/severe combined immunodeficient mice. Silencing endogenous KIF11 by short hairpin RNAs inhibited the proliferation of breast cancer cells in vitro and in vivo. The present results suggest that KIF11 may serve an important function in the proliferation of breast cancer and may represent a novel and useful prognostic marker for breast cancer.
\end{abstract}

\section{Introduction}

According to the National Cancer Institute, breast cancer was the most frequently diagnosed malignancy in 2015 (1). It is widely accepted that breast cancer develops when a series of gene disorders occur (2). It was demonstrated that breast cancer negative for murine double minute gene 2 and

Correspondence to: Dr Feng-Xiang Wei, Shenzhen Longgang Maternal and Child Health Hospital Centralab, 6240 Lung Cheung Road, Shenzhen, Guangdong 518172, P.R. China

E-mail: fengxiangwei1999@163.com

Key words: kinesin family member 11, breast cancer, progression, prognosis wild-type p53-activated fragment 1 expression, irrespective of p53 status, exhibited an increased response rate to docetaxel but no response to methotrexate and 5-fluorouracil, compared with breast cancer positive for murine double minute gene 2 and wild-type p53-activated fragment 1 expression (3). Immunohistochemical data has revealed that p53 mutation is the most common genetic alteration detected in primary breast cancer (4). Ertel et al (5) reported that retinoblastoma-loss signature expression is associated with poor outcome in breast cancer, but predicts improved response to chemotherapy based on data in oestrogen receptor (ER)-negative populations (5). Additionally, the Akt pathway is involved in the regulation of growth and migration of breast cancer (6). Oncogene Sam68 upregulation is associated with, and its downregulation inhibits, proliferation and tumorigenicity of breast cancer cells (7). Even so, a considerable number of patients succumb to breast cancer every year. New regulating factors that are targets for breast cancer therapy are urgently required.

KIF11, distributed throughout the cytoplasm (8), is a mitotic kinesin that plays a crucial role in the formation of bipolar mitotic spindles by hydrolysing ATP to push apart anti-parallel microtubules $(9,10)$. Previous studies reported that five mutations caused a broader spectrum of ocular disease, including retinal detachment (11-13). It has been hypothesized that KIF11 is involved in the progression of numerous diseases, including lymphedema (14), Alzheimer's disease (15), type 2 diabetes (16) and xeroderma pigmentosum (17). Wakana et al (18) revealed that disrupting the function of KIF11 in HeLa cells inhibited the secretion of pancreatic adenocarcinoma upregulated factor. KIF11 overexpression is associated with the poor differentiation of bladder cancer, and is an independent prognostic factor for predicting early intravesical recurrence in patients with non-muscle invasive bladder carcinoma (19). Dimethylenastron prevents the growth of pancreatic and lung cancer cells by halting mitotic progression and triggering apoptosis (9). Small molecule inhibitors of kinesin-5, which were developed as potential anti-cancer drugs, arrest cell cycle progression in mitosis and promote apoptosis of cancer cells (20). Additionally, the KIF11 inhibitor ARRY-520 may represent an alternative to paclitaxel in this subgroup of epithelial ovarian cancer patients (21-23). Overall, KIF11 was indicated to be involved in the progression and therapy of several types of cancer, including prostate cancer, colorectal cancer and gastric cancer (24-27). However, the expression state and effect of KIF11 on breast cancer 
remains unclear. As KIF11 plays an essential role in mitosis and is an interesting drug target against cancer, it is worthwhile to validate its role in breast cancer.

In the present study, it was revealed that the expression of KIF11 was overexpressed in human breast cancer cells and breast cancer tissues. Statistical analysis demonstrated a significant association between the upregulation of KIF11 expression and the progression of breast cancer. Multivariate analysis revealed that KIF11 upregulation may be an independent prognostic indicator for the survival of patients with breast cancer. Furthermore, silencing KIF11 with specific RNA interference (RNAi) inhibited the cell growth rate in vitro and in vivo. The present findings suggest that KIF11 serves an important function in the proliferation and tumorigenesis of human breast cancer, indicating that KIF11 may represent a valuable target for human breast cancer treatment.

\section{Materials and methods}

Cell lines and tissues. Primary normal breast epithelial cells (NBECs) were isolated from the mammoplasty material of two 32-year-old women at the Department of Plastic Surgery, Shenzhen Longgang Maternal and Child Health Hospital (Shenzhen, China) and cultured in the Keratinocyte serum-free medium (Invitrogen; Thermo Fisher Scientific, Inc., Waltham, MA, USA) (27,28). Breast cancer MDA-MB-453, T47D, MCF-7, ZR-75-30, MDA-MB-231 and BT-549 cell lines were cultured in DMEM medium (Invitrogen; Thermo Fisher Scientific, Inc.) supplemented with $10 \%$ fetal bovine serum (HyClone, Logan, Utah). Fresh tissues included six paired breast cancer tissues and adjacent non-tumour tissues obtained from individuals diagnosed with breast cancer at Shenzhen Longgang Maternal and Child Health Hospital (Shenzhen, China) between March 2013 and June 2014.

A total of 268 paraffin-embedded, archived breast cancer tissues were also collected, including 37 cases of low histological grade, 111 cases of intermediate histological grade and 120 cases of high histological grade. Samples were histopathologically and clinically diagnosed at the Shenzhen Longgang Maternal and Child Health Hospital between March 2003 and December 2013, were also used in the current study. Patient consent and approval from the Institutional Research Ethics Committee were obtained prior to the use of these clinical specimens for research purposes.

RNA extraction, reverse transcription $(R T)$ and quantitative polymerase chain reaction ( $q P C R$ ). Total RNA from cultured cells was extracted using the TRIzol reagent (Invitrogen; Thermo Fisher Scientific, Inc.) as the manufacturer instructed. cDNA was amplified using the cDNA Synthesis kit manual (cat. no. 6130 Takara Biotechnology Co., Ltd.- Dalian, China) according to the manufacturer's protocol, and quantified using an ABI Prism 7500 Sequence Detection system (Applied Biosystems, Foster City, CA) using the dye SYBR Green I (Invitrogen; Thermo Fisher Scientific, Inc.). PCR cycling conditions were $50^{\circ} \mathrm{C}$ for $2 \mathrm{~min}$, followed by $95^{\circ} \mathrm{C}$ for $10 \mathrm{~min}$ and then 40 cycles for $95^{\circ} \mathrm{C}$ for $15 \mathrm{sec}$ and $60^{\circ} \mathrm{C}$ for $1 \mathrm{~min}$. The primers used were: KIF11 forward, 5'-TATTGAATG GGCGCTAGCTT-3' and reverse, 5'-TCGTCTGCGAAGAAG AAAGA-3'; and GAPDH forward, 5'-ACCACAGTCCATGCC
ATCAC-3' and reverse, 5'-TCCACCACCCTGTTGCTGTA-3'. Expression data were normalized to that of the housekeeping gene GAPDH to control the variability in expression levels and calculated using the $2^{-\Delta \Delta \mathrm{Cq}}$ method (28).

Western blot analysis. Western blotting was performed according to standard methods, as described previously (29), using anti-KIF11 (cat. no. sc-365593) and anti-mouse horseradish peroxidase (HRP)-conjugated immunoglobulin (Ig) G (cat. no. sc-516102) antibodies (all 1:800; Santa Cruz Biotechnology, Inc., Dallas, TX, USA). The membranes were stripped and re-probed with an anti- $\beta$-actin mouse monoclonal antibody (1:2,000; cat. no. A2228; Sigma-Aldrich; Merck KGaA, Darmstadt, Germany) as a loading control. The expression of indicated proteins was determined using an enhanced chemiluminescence kit (cat. no. 3622ES60; Pierce, Thermo Fisher Scientific, Inc.) according to the manufacturer's protocol. ImageJ 1.48 software (National Institutes of Health, Bethesda, MD, USA) was used to perform densitometry analysis. All detections were performed in triplicate.

Plasmids and retroviral infection. For the depletion of KIF11, twohumansiRNA sequenceswere clonedintopSuper-retro-puro (provided by Professor Le Yang, Nanyang Medical College, Singapore) (30) to generate pSuper-retro-KIF11-RNAi\#1 and \#2, and the sequences were as follows: RNAi\#1, 5'-UAUGGU GUUUGGAGCAUCUAC UAAA-3'; and RNAi\#2, 5'-CAG UACACAACAAGGAUG AAGUCUA-3' (Invitrogen; Thermo Fisher Scientific, Inc.). Retroviral production and infection were performed as previously described (7).

Immunohistochemistry (IHC). The IHC procedure and the KIF11 expression scores in the 268 paraffin-embedded breast cancer samples, including 37 cases of low histological grade, 111 cases of intermediate histological grade and 120 cases of high histological grade, were performed as previously described (31). Anti-KIF11 and anti-mouse HRP-linked IgG (1:150; Santa Cruz Biotechnology, Inc.) antibodies were used in this assay. Staining for protein expression in tumor and normal tissues was quantitative analyzed using the AxioVision Rel.4.6 computerized image analysis system assisted with the automatic measurement program (Zeiss AG, Oberkochen, Germany). Ten representative staining fields of each section were analyzed to verify the mean optical density (MOD), and the MOD data were statistically analyzed using a t-test to compare the average MOD difference between different groups of tissues.

MTT assay. MCF-7-vector, MCF-7-KIF11 RNAi-1, MCF-7KIF11 RNAi-2, MDA-MB-231-vector, MDA-MB-231-KIF11 RNAi-1 and MDA-MB-231-KIF11 RNAi-2 cells were seeded on 96 -well plates $\left(0.2 \times 10^{4}\right.$ cells/well $)$. At each time point, cells were stained with MTT dye $(0.5 \mathrm{mg} / \mathrm{ml}$ Sigma-Aldrich; Merck $\mathrm{KGaA}$ ) for $4 \mathrm{~h}$ at $37^{\circ} \mathrm{C}$, followed by the removal of the culture medium and addition of $150 \mu$ l dimethyl sulfoxide (Sigma-Aldrich; Merck KGaA). The absorbance was measured at $570 \mathrm{~nm}$, with $655 \mathrm{~nm}$ used as the reference wavelength. All experiments were performed in triplicate.

Anchorage-independent growth ability assay. A total of 500 MCF-7-vector, MCF-7-KIF11 RNAi-1, MCF-7-KIF11 
RNAi-2, MDA-MB-231-vector, MDA-MB-231-KIF11 RNAi-1 and MDA-MB-231-KIF11 RNAi-2 cells were trypsinized and suspended in $2 \mathrm{ml}$ complete medium plus $0.3 \%$ agar (Sigma-Aldrich; Merck KGaA). After 10 days, viable colonies that contained $>50$ cells or were larger than $0.5 \mathrm{~mm}$ were counted. All experiments were performed in triplicates.

Colony formation assays. MCF-7-vector, MCF-7-KIF11 RNAi-1, MCF-7-KIF11 RNAi-2, MDA-MB-231-vector, MDA-MB-231-KIF11 RNAi-1 and MDA-MB-231-KIF11 RNAi- 2 cells were plated on $60-\mathrm{mm}$ plates $\left(0.5 \times 10^{3}\right.$ cells per plate) and cultured at $37^{\circ} \mathrm{C}$ for 10 days. The colonies were stained with $1 \%$ crystal violet (Sigma-Aldrich; Merck KGaA) for $30 \mathrm{sec}$ following fixation with $10 \%$ formaldehyde for $5 \mathrm{~min}$ at room temperature.

Xenograft tumour model. Each mouse was subcutaneously injected in situ with MDA-MB-231-vector cells (5x106 cells) on the left flank and with MDA-MB-231-KIF11 cells $\left(5 \times 10^{6}\right.$ cells) on the right flank. Tumours were examined every five days. The length (L) and width (W) were measured using calipers, and tumour volumes were calculated using the following equation: Tumour volume $\left(\mathrm{cm}^{3}\right)=\left(\mathrm{LxW}^{2}\right) / 2$. On day 35 , the animals were euthanized, and the tumours were excised and weighed. The Institutional Animal Care and Use Committee of Shenzhen Longgang Maternal and Child Health Hospital approved all experimental procedures.

Statistical analysis. All statistical analyses were performed using SPSS 13.0 statistical software (SPSS, Inc., Chicago, IL, USA). The association between KIF11 expression and clinicopathological characteristics was analyzed using the $\chi^{2}$ test. Bivariate correlations between study variables were calculated using Spearman's rank correlation coefficients. Survival curves were plotted using the Kaplan-Meier method and compared using the log-rank test. Survival data were evaluated using univariate and multivariate Cox regression analyses. $\mathrm{P}<0.05$ was considered to indicate a statistically significant difference.

\section{Results}

KIF11 is upregulated in breast cancer cell lines. To assess the expression of KIF11, normal breast epithelial cells (NBEC) from two different patients without breast cancer were obtained and cultured. Western blot analysis and RT-qPCR analysis revealed that KIF11 expression was extremely difficult to detect in NBECs. Breast cancer cell lines were used to detect the expression of KIF11 protein and mRNA in malignant cells. As shown in Fig. 1A, the protein level of KIF11 was markedly upregulated in six breast cancer cells lines, consisting of the MDA-MB-453, T47D, MCF-7, ZR-75-30, MDA-MB-231 and BT-549 cell lines, in comparison to those in NBEC1 and NBEC2. RT-qPCR analysis also revealed similar results of mRNA expression in the breast cancer cell lines MDA-MB-453, T47D, MCF-7, ZR-75-30, MDA-MB-231 and BT-549, with a 4.7-14.9 fold increase compared with that in the NBEC1 cells (Fig. 1B).

KIF11 is upregulated in paired fresh tissues of breast cancer. Six pairs of matched adjacent non-tumorous breast tissue
Table I. Association between KIF11 expression and clinicopathological characteristics of breast cancer patients.

\begin{tabular}{|c|c|c|c|c|}
\hline \multirow[b]{2}{*}{ Characteristics } & \multirow[b]{2}{*}{ Total, $\mathrm{n}$} & \multicolumn{2}{|c|}{$\begin{array}{c}\text { KIF11 } \\
\text { expression, } \mathrm{n}\end{array}$} & \multirow[b]{2}{*}{ P-value } \\
\hline & & Low & High & \\
\hline Age & & & & 0.685 \\
\hline$<45$ years & 101 & 30 & 71 & \\
\hline$\geq 45$ years & 167 & 54 & 113 & \\
\hline Clinical stage & & & & $<0.001$ \\
\hline I & 25 & 24 & 1 & \\
\hline II & 126 & 43 & 83 & \\
\hline III & 79 & 11 & 68 & \\
\hline IV & 31 & 3 & 28 & \\
\hline T classification & & & & $<0.001$ \\
\hline $\mathrm{T} 1$ & 44 & 29 & 15 & \\
\hline $\mathrm{T} 2$ & 141 & 44 & 97 & \\
\hline T3 & 50 & 8 & 42 & \\
\hline $\mathrm{T} 4$ & 26 & 0 & 26 & \\
\hline $\mathrm{N}$ classification & & & & $<0.001$ \\
\hline No & 106 & 56 & 50 & \\
\hline $\mathrm{N} 1$ & 101 & 15 & 86 & \\
\hline N2 & 43 & 8 & 35 & \\
\hline N3 & 11 & 2 & 9 & \\
\hline Metastasis & & & & 0.042 \\
\hline No & 246 & 80 & 166 & \\
\hline Yes & 15 & 1 & 14 & \\
\hline Histological grade & & & & $<0.001$ \\
\hline Low & 37 & 22 & 15 & \\
\hline Intermediate & 111 & 48 & 63 & \\
\hline High & 120 & 14 & 106 & \\
\hline ER & & & & 0.088 \\
\hline Negative & 32 & 91 & 123 & \\
\hline Positive & 52 & 93 & 145 & \\
\hline PR & & & & 0.107 \\
\hline Negative & 107 & 28 & 79 & \\
\hline Positive & 156 & 56 & 100 & \\
\hline erbB-2 & & & & 1.000 \\
\hline Negative & 38 & 10 & 28 & \\
\hline Positive & 115 & 30 & 84 & \\
\hline
\end{tabular}

KIF11, kinesin family member 11; T, tumour; N, node; ER, oestrogen receptor; $\mathrm{PR}$, progesterone receptor.

(ANT) and breast tumour tissue samples were used for screening the expression of KIF11. Western blot and RT-qPCR analysis revealed that the protein and mRNA levels of KIF11 were significantly upregulated in the human primary breast tumour tissues, with a $\geq 2.5$-fold increase compared with each paired ANT (Fig. 2A and B). The in situ expression of KIF11 in the aforementioned six pairs of breast tissues was examined by immunohistochemical staining. The representative 
brown colour in Fig. 2C indicated the expression of the KIF11 protein, confirming the upregulation of KIF11 in breast cancer. However, the IHC signal of KIF11 was undetectable or only marginally detectable in the ANTs. Overall, the present results indicated that KIF11 expression was upregulated in breast cancer cell lines and breast cancer tissues.

Upregulation of KIF11 is associated with clinicopathological characteristics of breast cancer and patient survival. To validate the universality and importance of the upregulation of KIF11 in breast cancer, 268 paraffin-embedded, archived breast cancer tissues were also collected, including 37 cases of low histological grade, 111 cases of intermediate histological grade and 120 cases of high histological grade. These samples were stained with KIF11 antibody, scored by a recognized standard and summarized in Table I. As shown in Fig. 3A, KIF11 protein expression was detected in 256 of the 268 $(95.5 \%)$ tested cases, which was expressed at lower levels in early stages (stage I-II) and more highly expressed in later stages (stage III-IV). Quantitative analysis indicated that the average mean optical densities (MODs) of KIF11 staining were markedly increased in breast tumours compared with the MODs of normal breast tissues ( $\mathrm{P}<0.001$; Fig. 3B). Overall, the present results indicate that overexpression of KIF11 is a common feature of breast cancer.

Furthermore, the IHC score and classification (low expression of KIF11; intensive expression of KIF11) of the expression of KIF11 in the IHC assays were statistical analysed to evaluate the association between KIF11 and the clinicopathological characteristics of breast cancer. As shown in Table I, there was a strong association between the expression of KIF11 and clinical stage $(\mathrm{P}<0.001)$, $\mathrm{T}$ classification $(\mathrm{P}<0.001), \mathrm{N}$ classification $(\mathrm{P}<0.001)$ and $\mathrm{M}$ classification $(\mathrm{P}=0.042)$. However, the expression of KIF11 is not associated with ER, PR or ErbB-2 expression.

Additionally, the effects of clinicopathological characteristics and the expression of KIF11 protein on survival were analysed using Kaplan-Meier analysis and the log-rank test. As shown in Fig. 3C, the survival time was evidently longer in the patients with low expression of KIF11 $(\mathrm{P}<0.001)$. Statistical analysis presented in Table II revealed an inverse association between KIF11 level and patient survival $(\mathrm{P}=0.005)$. Furthermore, log-rank test and Kaplan-Meier analysis were also applied to calculate the effect of KIF11 expression and histological staging of breast cancer on survival in more detail. The log-rank test showed that the expression level of KIF11 protein in breast cancer was significantly associated with the survival time of patients $(\mathrm{P}<0.001)$. In particular, the mean survival time of patients with high expression of the KIF11 protein was only 92.42 months, whereas the mean survival time of those with low levels of KIF11 expression was 127.49 months. As shown in Fig. 2C, the cumulative survival rate was significantly increased in the low KIF11 expression group compared with the high KIF11 expression group. Multivariate survival analysis shown in Table III indicated that the KIF11 expression level was an independent prognostic factor for the assessment of patient outcomes. This finding suggested that KIF11 acted as a prognostic factor, which may be useful to predict cancer evolution and provide appropriate treatments for breast cancer patients.
Table II. Clinical pathological parameters and expression of KIF11 for prognosis of 268 patients with breast cancer by univariate survival analysis.

\begin{tabular}{|c|c|c|c|c|}
\hline Characteristics & $\begin{array}{c}\text { Total, } \\
\mathrm{n}\end{array}$ & $\begin{array}{c}\text { Mean } \\
\text { survival } \\
\text { time, } \\
\text { months }\end{array}$ & $\begin{array}{c}\text { Median } \\
\text { survival } \\
\text { time, } \\
\text { months }\end{array}$ & P-value \\
\hline Age & & & & 0.219 \\
\hline$<45$ years & 101 & 104.78 & 116 & \\
\hline$\geq 45$ years & 167 & 102.59 & 118 & \\
\hline Clinical stage & & & & $<0.001$ \\
\hline I & 25 & 123.68 & 122 & \\
\hline II & 126 & 113.13 & 120 & \\
\hline III & 79 & 90.53 & 106 & \\
\hline IV & 31 & 87.1 & 102 & \\
\hline $\mathrm{T}$ classification & & & & $<0.001$ \\
\hline $\mathrm{T} 1$ & 44 & 109.16 & 120 & \\
\hline $\mathrm{T} 2$ & 141 & 113.85 & 120 & \\
\hline $\mathrm{T} 3$ & 50 & 94.64 & 108 & \\
\hline $\mathrm{T} 4$ & 26 & 61.92 & 46 & \\
\hline $\mathrm{N}$ classification & & & & $<0.001$ \\
\hline No & 106 & 116.78 & 120 & \\
\hline N1 & 101 & 103.42 & 118 & \\
\hline $\mathrm{N} 2$ & 43 & 76.37 & 82 & \\
\hline N3 & 11 & 99.09 & 122 & \\
\hline Metastasis & & & & $<0.001$ \\
\hline No & 246 & 107.07 & 120 & \\
\hline Yes & 15 & 57.2 & 40 & \\
\hline Histological grade & & & & $<0.001$ \\
\hline Low & 37 & 152.11 & 148 & \\
\hline Intermediate & 111 & 125.06 & 124 & \\
\hline High & 120 & 68.38 & 66 & \\
\hline KIF11 expression & & & & $<0.001$ \\
\hline Low & 84 & 127.49 & 124 & \\
\hline High & 181 & 92.42 & 107 & \\
\hline
\end{tabular}

KIF11, kinesin family member 11 ; $\mathrm{T}$, tumour; $\mathrm{N}$, node

Downregulation of endogenous KIF11 inhibited the proliferation of breast cancer cells. To investigate the biological role of KIF11 expression in the development and progression of breast cancer, two specific KIF11-short hairpin (sh)RNAs were transfected into breast cancer MCF-7 and MDA-MB-231 cell lines to further investigate the effect of KIF11 in promoting proliferation of breast cancer (Fig. 4A). MTT assay revealed that downregulation of KIF11 significantly slowed down the proliferation of breast cancer MCF-7 and MDA-MB-231 cells, with $\sim 1.5$-fold fewer cells than the control by day 5 subsequent to plating (185 vs. $365 \%$ MTT absorbance in MCF-7 cells and 155 vs. 337\% MTT absorbance in MDA-MB-231 cells; Fig. 4B). As shown in Fig. 4C, the colony number was also significantly decreased in the KIF11-transfected cells. These experiments show that inhibition of KIF11 markedly 
A

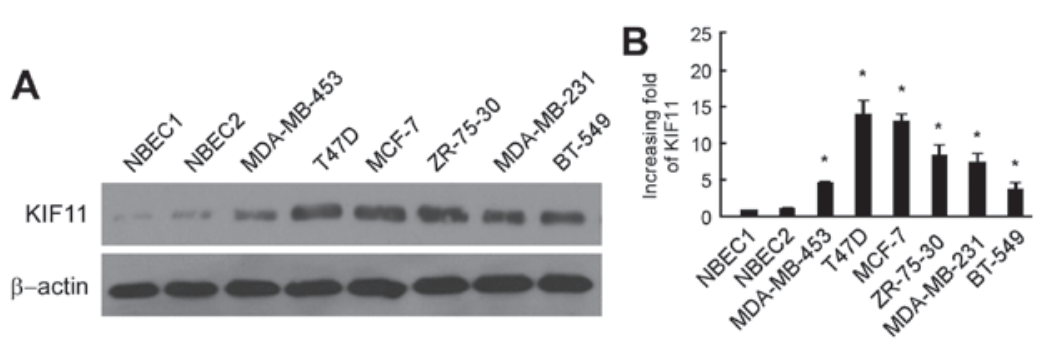

Figure 1. Expression analysis of KIF11 protein and mRNA in breast cancer cells. (A) Western blot analysis of KIF11 protein expression in two NBEC and breast cancer cell lines. NBECs were used as the negative control. (B) Expression of KIF11 mRNA in NBECs and breast cancer cell lines. KIF11, kinesin family member 11; NBEC, normal breast epithelial cells.

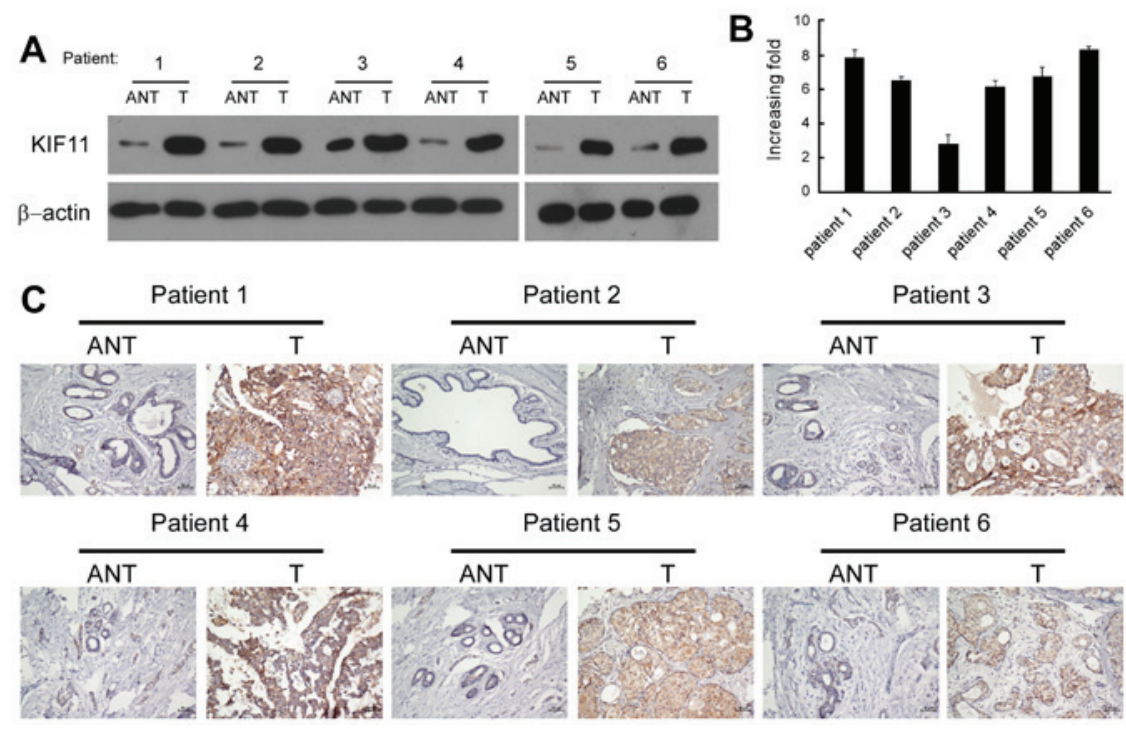

Figure 2. Expression analysis of KIF11 protein and mRNA in breast cancer tissues paired with ANT. (A) Western blot investigation of expression of KIF11 protein in six paired breast cancer tissues. $\beta$-actin was used the loading control. (B) Reverse transcription-quantitative polymerase chain reaction analysis of KIF11 expression in the indicated fresh tissues. GAPDH was used as the loading control. (C) Immunohistochemical staining of KIF11 protein in the indicated primary tissues. P<0.05 vs. ANT. KIF11, kinesin family member 11; ANT, adjacent non-tumorous tissues; T, breast cancer tissues.

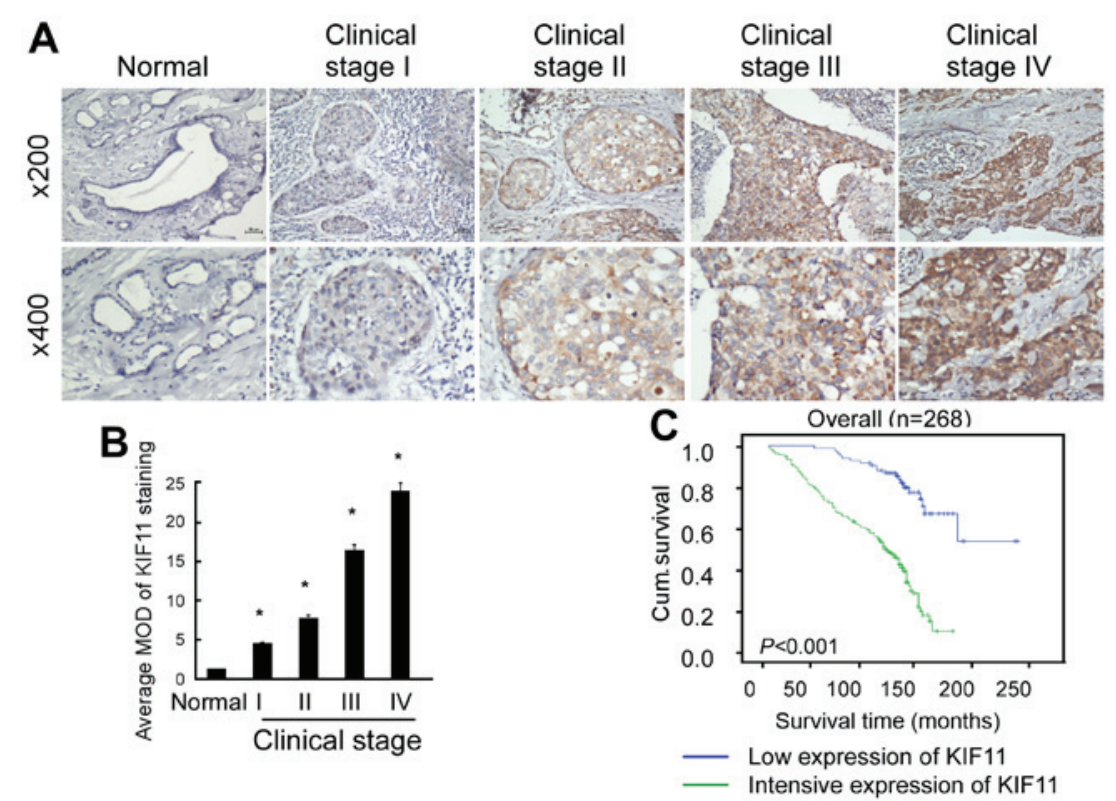

Figure 3. Overexpression of KIF11 in archived breast cancer tissues. (A) Representative immunohistochemistry of KIF11 expression in normal breast tissue and breast cancer specimens of different clinical stages. (B) Statistical quantification of the average MOD of KIF11 staining between normal breast tissues and breast cancer specimens of different clinical stages. The average mean absorbance of KIF11 staining increases as breast cancer progresses to a higher clinical stage. (C) Kaplan-Meier curves with univariate analyses (log-rank test) for patients with low KIF11 expression vs. intensive KIF11 expression. KIF11, kinesin family member 11; MOD, mean optical density. 

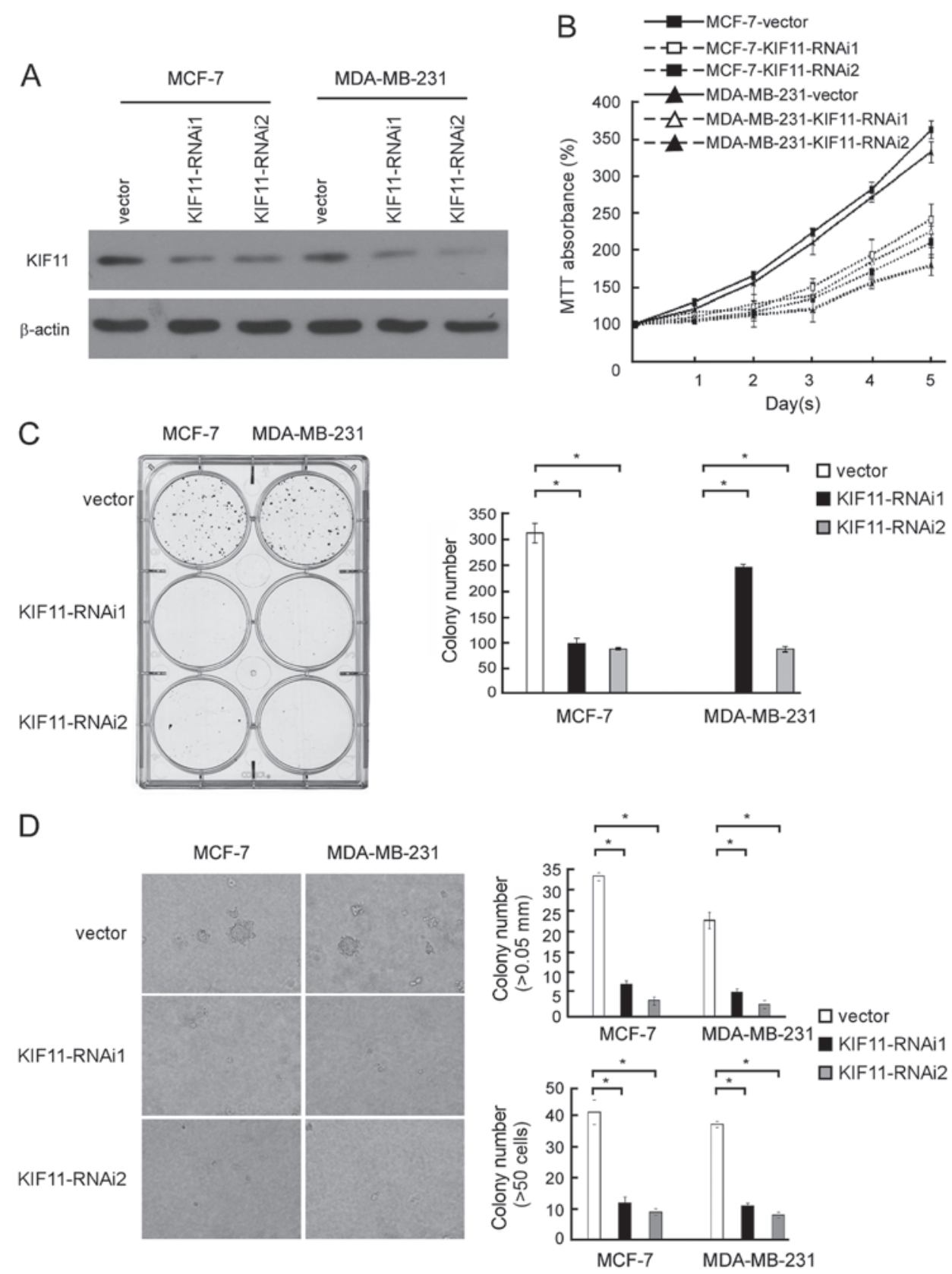

Figure 4. Downregulation of endogenous KIF11 suppressed MCF-7 and MDA-MB-231 cell proliferation in vitro. (A) Western blot analysis of increased KIF11 expression. (B) MTT assay showing that KIF11-transfected cells grew slower than vector-transfected cells. (C) Representative micrographs and quantification of crystal violet-stained cell colonies. (D) Representative micrographs and colony numbers in the anchorage-independent growth assay. Each bar represents the mean of three independent experiments. " $\mathrm{P}<0.05$ vs. vector. KIF11, kinesin family member 11.

reduced the growth rate of MCF-7 and MDA-MB-231 cells compared with the growth rate of vector-transfected cells. As shown in Fig. 4D, decreased colony number and colony size in KIF11-shRNA-transfected breast cancer cells was identified and indicated the inhibition effect of downregulation of KIF11 on anchorage-independent growth ability $(\mathrm{P}<0.05)$. These results further supported the hypothesis that KIF11 serves important functions in the proliferation and tumorigenicity of breast cancer cells.

In vivo assay reveals the inhibition role of KIF11-RNAi on tumorigenicity. To validate the aforementioned results obtained from the in vitro cell proliferation assays, the present study performed in vivo assays to evaluate the tumorigenic effect of KIF11 in BALB/C nude mice using the MDA-MB-231 cell line. As shown in Fig. 5A, KIF11-RNAi\#1-transfected cells showed an anti-proliferation tendency in nude mice. Decreased tumour volume and tumour weight generated from KIF11-RNAi\#1-transfected cells were observed compared with the vector infected group, as indicated in Fig. 5B and C. Overall, the present results demonstrated that KIF11 has an important role in the tumorigenicity of nude mice.

\section{Discussion}

The key finding of the present study is that the progression of human breast cancer is associated with the upregulation of KIF11. Furthermore, in vitro and in vivo assays both 
Table III. Multivariate analysis of overall survival (Cox regression model).

\begin{tabular}{lccc}
\hline Variable & $\begin{array}{c}\text { Relative } \\
\text { risk }\end{array}$ & $\begin{array}{c}95 \% \\
\text { confidence } \\
\text { interval }\end{array}$ & P-value \\
\hline KIF11 & 3.177 & $1.684-5.991$ & $<0.001$ \\
T classification & 0.758 & $0.423-1.359$ & 0.01 \\
N classification & 1.233 & $0.502-3.029$ & 0.005 \\
Metastasis & 0.215 & $0.111-0.417$ & $<0.001$ \\
Histological grade & 0.03 & $0.014-0.062$ & $<0.001$ \\
\hline
\end{tabular}

KIF11, kinesin family member 11 .

demonstrated that the promoting effect of KIF11 on breast cancer cells and may indicate a novel predictive marker for the clinical outcome of the disease.

Previous studies have associated KIF11 expression with cancer development and progression. Upregulation of the KIF11 protein and mRNA levels was reported in prostate cancer PC 3 cells. In the PC 3 and LNCaP cell lines, deceased mRNA and protein levels of KIF11 inhibited cell growth, induced $\mathrm{G} 2 / \mathrm{M}$ phase arrest and increased the apoptotic sub-G1 fraction. In vivo, decreased KIF11 significantly reduced both $\mathrm{LNCaP}$ and PC-3 tumour growth (32). Other studies may be utilized to clarify the mechanisms of KIF11 in cancer progression. It was reported that, in CD4-positive T-lymphocytes, Tat interacts with KIF11 and allosterically modulates the ATPase activity of KIF11 by affecting ADP release from the active centre of the enzyme. This action of Tat impairs the formation of the mitotic spindle and activates the spindle checkpoint, thereby blocking cell cycle progression at mitosis and leading to apoptosis (33). Sun et al (34) revealed that the expression of KIF11 in renal cell carcinoma was significantly associated with tumour nuclear grade and stage, as well as tumour size. In univariate analysis, KIF11 overexpression showed a statistically significant unfavourable effect on recurrence-free survival (34). It was identified by Bartoli et al (35) that, during interphase, KIF11 is associated with ribosomes and is required for optimal nascent polypeptide synthesis. When KIF11 was inhibited, ribosomes no longer bound to microtubules in vitro, ribosome transit rates slowed, and polysomes accumulated in intact cells, suggesting defects in elongation or termination during polypeptide synthesis. Furthermore, cycle-dependent kinase 1 (CDK1) and CDK2 phosphorylated KIF11 at Thr927, which supports the association between KIF11 and cell-cycle regulation (36). Additionally, nucleophosmin/B23, an abundant nucleolar protein, has multiple roles in cell growth and proliferation. Both in vivo and in vitro studies have demonstrated that B23 acts as an upstream regulator of KIF11 in promoting microtubule polymerization. Additionally, it was further demonstrated that B23 regulates microtubule dynamics by directly inhibiting ATPase activity (37). The present study found that KIF11 was frequently upregulated in breast cancer and the positive association between the progression of breast cancer and the expression of KIF11.
A

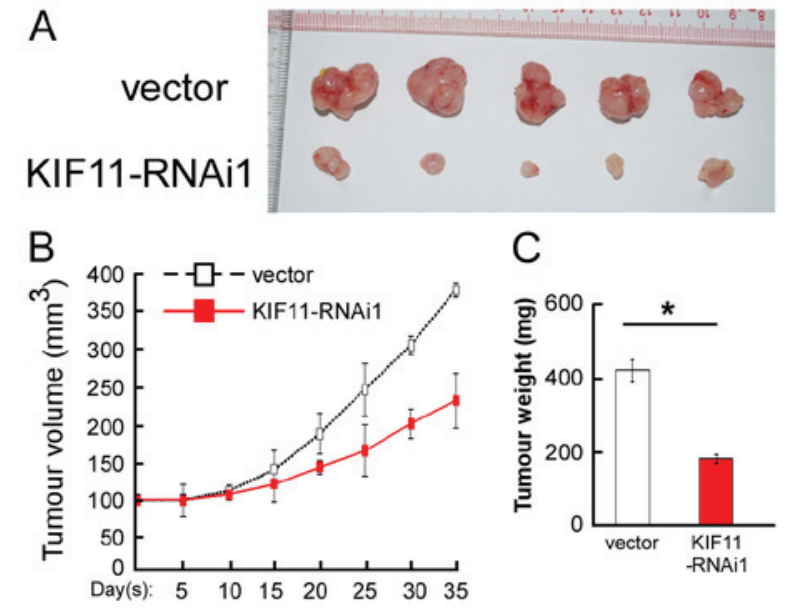

Figure 5. In vivo assays of the effect of KIF11 on cell proliferation. (A) Excised tumours 35 days subsequent to injection into non-obese diabetic/severe combined immunodeficient mice. (B) Tumour growth curve measured every 5 days. (C) The average weight of the excised tumours in the group injected with vector-transfected cells or KIF11-RNAi1-transfected cells. ${ }^{*} \mathrm{P}<0.05$ vs. vector.

In the more detailed survival analysis of the present study, multivariate analyses have shown that high expression of KIF11 is a predictor of poor prognosis for breast cancer patients. Nevertheless, the mechanism of the regulation of KIF protein in the progression of breast cancer requires additional study.

Numerous studies have indicated that KIF11 is a feasible drug target. It was reported that KIF11 has a critical role in mitosis as it mediates centrosome separation and bipolar spindle assembly and maintenance $(38,39)$. Knockdown of KIF11 by siRNA and SB-715992, another term for the small-molecule inhibitor ispinesib, both induced G2 arrest. Furthermore, growth of head and neck squamous cell carcinoma cells engrafted in immunodeficient mice was significantly inhibited after ispinesib treatment (40). Marra et al (41) found that KIF-specific siRNA markedly reduced outgrowth of subcutaneous melanoma and ovarian cancer lesions. The ispinesib analogue 1 , a well characterized and potentially specific small molecule inhibitor of KIF11, showed an anti-proliferative effect on glioblastoma multiforme cell lines by blocking cell cycle progression in the $\mathrm{G} 2 / \mathrm{M}$ phase and increased caspase 3/7-induced apoptosis in U87MG cells (42). In addition, the kinesin spindle protein (KSP) inhibitor ARRY-520 may be an alternative to paclitaxel in a Type I ovarian cancer patients (23). Inhibition of KSP by ARRY-520 induces cell cycle block and cell death via the mitochondrial pathway in AML cells (22). Comparison between KSP inhibitor-induced apoptosis in matched cell lines containing functional p53 and cells containing deficient p53 revealed that inhibition of KSP induces apoptosis independently of p53, and that p53 is dispensable for spindle checkpoint function. Thus, KIF11 inhibitors should be active in p53-deficient tumours (43). However, it is rare for studies to focus on the inhibition of KIF11 in breast cancer. In the present study, it was found that downregulation of endogenous KIF11 inhibited the proliferation of breast cancer cells in vitro and in vivo, indicating that KIF11 may be a valuable target for human breast cancer treatment. 
In summary, the present study suggests that KIF11 overexpression is a common feature in breast cancer and may be a potential target as a therapeutic strategy for breast cancer.

\section{Acknowledgements}

The present study was supported by the National Natural Science Foundation of China (grant no. 81201568).

\section{References}

1. Stuckey AR and Onstad MA: Hereditary breast cancer: An update on risk assessment and genetic testing in 2015. Am J Obstet Gynecol 213: 161-165, 2015.

2. Sutherland RL, Hamilton JA, Sweeney KJ, Watts CK and Musgrove EA: Expression and regulation of cyclin genes in breast cancer. Acta Oncol 34: 651-656, 1995.

3. Sjöström J, Blomqvist C, Heikkilä P, Boguslawski KV, Räisänen-Sokolowski A, Bengtsson NO, Mjaaland I, Malmström P, Ostenstadt B, Bergh J, et al: Predictive value of $\mathrm{p} 53, \mathrm{mdm}-2, \mathrm{p} 21$, and mib-1 for chemotherapy response in advanced breast cancer. Clin Cancer Res 6: 3103-3110, 2000

4. Bartek J, Iggo R, Gannon J and Lane DP: Genetic and immunochemical analysis of mutant p53 in human breast cancer cell lines. Oncogene 5: 893-899, 1990.

5. Ertel A, Dean JL, Rui H, Liu C, Witkiewicz AK, Knudsen KE and Knudsen ES: RB-pathway disruption in breast cancer: Differential association with disease subtypes, disease-specific prognosis and therapeutic response. Cell Cycle 9: 4153-4163, 2010.

6. Tomas NM, Masur K, Piecha JC, Niggemann B and Zänker KS: Akt and phospholipase $\mathrm{C} \gamma$ are involved in the regulation of growth and migration of MDA-MB-468 breast cancer and SW480 colon cancer cells when cultured with diabetogenic levels of glucose and insulin. BMC Res Notes 5: 214, 2012.

7. Song L, Wang L, Li Y, Xiong H, Wu J, Li J and Li M: Sam68 up-regulation correlates with, and its down-regulation inhibits, proliferation and tumourigenicity of breast cancer cells. J Pathol 222: 227-237, 2010.

8. Iwakiri Y, Kamakura S, Hayase J and Sumimoto H: Interaction of NuMA protein with the kinesin Eg5: It's possible role in bipolar spindle assembly and chromosome alignment. Biochem J 451: 195-204, 2013.

9. Sun L, Sun X, Xie S, Yu H and Zhong D: Significant decrease of ADP release rate underlies the potent activity of dimethylenastron to inhibit mitotic kinesin Eg5 and cancer cell proliferation. Biochem Biophys Res Commun 447: 465-470, 2014.

10. McGrath MJ, Kuo IF, Hayashi S and Takada S: Adenosine triphosphate hydrolysis mechanism in kinesin studied by combined quantum-mechanical/molecular-mechanical metadynamics simulations. J Am Chem Soc 135: 8908-8919, 2013.

11. Robitaille JM, GillettRM,LeBlanc MA, Gaston D, Nightingale M, Mackley MP, Parkash S, Hathaway J, Thomas A, Ells A, et al: Phenotypic overlap between familial exudative vitreoretinopathy and microcephaly, lymphedema, and chorioretinal dysplasia caused by KIF11 mutations. JAMA Ophthalmol 132: 1393-1399, 2014.

12. Hazan F, Ostergaard P, Ozturk T, Kantekin E, Atlihan F, Jeffery S and Ozkinay F: A novel KIF11 mutation in a Turkish patient with microcephaly, lymphedema, and chorioretinal dysplasia from a consanguineous family. Am J Med Genet A 158A: 1686-1689, 2012.

13. Riedl J, Voßmerbäumer U, Stoffelns B and Elflein H: Total retinal detachment caused by a KIF11 mutation. Eur J Ophthalmol: May 24, 2017 (Epub ahead of print)

14. Jones GE, Ostergaard P, Moore AT, Connell FC, Williams D, Quarrell O, Brady AF, Spier I, Hazan F, Moldovan O, et al: Microcephaly with or without chorioretinopathy, lymphoedema, or mental retardation (MCLMR): Review of phenotype associated with KIF11 mutations. Eur J Hum Genet 22: 881-887, 2014

15. Bullock JM, Medway C, Cortina-Borja M, Turton JC, Prince JA, Ibrahim-Verbaas CA, Schuur M, Breteler MM, van Duijn CM, Kehoe PG, et al: Discovery by the Epistasis Project of an epistatic interaction between the GSTM3 gene and the HHEX/IDE/KIF11 locus in the risk of Alzheimer's disease. Neurobiol Aging 34: 1309.e1-e7, 2013
16. Qian Y, Lu F, Dong M, Lin Y, Li H, Chen J, Shen C, Jin G, Hu Z and Shen H: Genetic variants of IDE-KIF11-HHEX at 10q23.33 associated with type 2 diabetes risk: A fine-mapping study in Chinese population. PLoS One 7: e35060, 2012.

17. Tan LJ, Saijo M, Kuraoka I, Narita T, Takahata C, Iwai S and Tanaka K: Xeroderma pigmentosum group $\mathrm{F}$ protein binds to $\mathrm{Eg} 5$ and is required for proper mitosis: Implications for XP-F and XFE. Genes Cells 17: 173-185, 2012.

18. Wakana Y, Villeneuve J, van Galen J, Cruz-Garcia D, Tagaya M and Malhotra V: Kinesin-5/Eg5 is important for transport of CARTS from the trans-Golgi network to the cell surface. J Cell Biol 202: 241-250, 2013

19. Ding S, Xing N, Lu J, Zhang H, Nishizawa K, Liu S, Yuan X, Qin Y, Liu Y, Ogawa O, et al: Overexpression of Eg5 predicts unfavorable prognosis in non-muscle invasive bladder urothelial carcinoma. Int J Urol 18: 432-438, 2011.

20. Tsui M, Xie T, Orth JD, Carpenter AE, Rudnicki S, Kim S, Shamu CE and Mitchison TJ: An intermittent live cell imaging screen for siRNA enhancers and suppressors of a kinesin-5 inhibitor. PLoS One 4: e7339, 2009.

21. Woessner R, Tunquist B, Lemieux C, Chlipala E, Jackinsky S, Dewolf W Jr, Voegtli W, Cox A, Rana S, Lee P and Walker D: ARRY-520, a novel KSP inhibitor with potent activity in hematological and taxane-resistant tumor models. Anticancer Res 29: 4373-4380, 2009

22. Carter BZ, Mak DH, Woessner R, Gross S, Schober WD, Estrov Z, Kantarjian H and Andreeff M: Inhibition of KSP by ARRY-520 induces cell cycle block and cell death via the mitochondrial pathway in AML cells. Leukemia 23: 1755-1762, 2009.

23. Kim KH, Xie Y, Tytler EM, Woessner R, Mor G and Alvero AB: KSP inhibitor ARRY-520 as a substitute for Paclitaxel in Type I ovarian cancer cells. J Transl Med 7: 63, 2009.

24. Asbaghi Y, Thompson LL, Lichtensztejn Z and McManus KJ: KIF11 silencing and inhibition induces chromosome instability that may contribute to cancer. Genes Chromosomes Cancer 56: $668-680,2017$.

25. Schneider MA, Christopoulos P, Muley T, Warth A, Klingmueller U, Thomas M, Herth FJ, Dienemann $\mathrm{H}$, Mueller NS, Theis F, et al: AURKA, DLGAP5, TPX2, KIF11 and CKAP5: Five specific mitosis-associated genes correlate with poor prognosis for non-small cell lung cancer patients. Int J Oncol 50: 365-372, 2017.

26. Imai T, Oue N, Sentani K, Sakamoto N, Uraoka N, Egi H, Hinoi T, Ohdan H, Yoshida K and Yasui W: KIF11 is required for spheroid formation by oesophageal and colorectal cancer cells. Anticancer Res 37: 47-55, 2017.

27. Imai T, Oue N, Nishioka M, Mukai S, Oshima T, Sakamoto N, Sentani K, Matsusaki K, Yoshida K and Yasui W: Overexpression of KIF11 in gastric cancer with intestinal mucin phenotype. Pathobiology 84: 16-24, 2017.

28. Livak KJ and Schmittgen TD: Analysis of relative gene expression data using real-time quantitative PCR and the 2(-Delta Delta C(T)) method. Methods 25: 402-408, 2001

29. Li J, Zhang N, Song LB, Liao WT, Jiang LL, Gong LY, Wu J, Yuan J, Zhang HZ, Zeng MS and Li M: Astrocyte elevated gene-1 is a novel prognostic marker for breast cancer progression and overall patient survival. Clin Cancer Res 14: 3319-3326, 2008.

30. Li J, Yang L, Song L, Xiong H, Wang L, Yan X, Yuan J, Wu J and $\mathrm{Li} \mathrm{M}$ : Astrocyte elevated gene-1 is a proliferation promoter in breast cancer via suppressing transcriptional factor FOXO1. Oncogene 28: 3188-3196, 2009

31. Zhang Z, Li J, Zheng H, Yu C, Chen J, Liu Z, Li M, Zeng M, Zhou $\mathrm{F}$ and Song L: Expression and cytoplasmic localization of SAM68 is a significant and independent prognostic marker for renal cell carcinoma. Cancer Epidemiol Biomarkers Prev 18: 2685-2693, 2009

32. Hayashi N, Koller E, Fazli L and Gleave ME: Effects of Eg5 knockdown on human prostate cancer xenograft growth and chemosensitivity. Prostate 68: 1283-1295, 2008.

33. Liu M, Li D, Sun L, Chen J, Sun X, Zhang L, Huo L and Zhou J: Modulation of Eg5 activity contributes to mitotic spindle checkpoint activation and Tat-mediated apoptosis in CD4-positive T-lymphocytes. J Pathol 233: 138-147, 2014.

34. Sun D, Lu J, Ding K, Bi D, Niu Z, Cao Q, Zhang J and Ding S: The expression of Eg5 predicts a poor outcome for patients with renal cell carcinoma. Med Oncol 30: 476, 2013.

35. Bartoli KM, Jakovljevic J, Woolford JL Jr and Saunders WS: Kinesin molecular motor Eg5 functions during polypeptide synthesis. Mol Biol Cell 22: 3420-3430, 2011. 
36. Smith E, Hégarat N, Vesely C, Roseboom I, Larch C, Streicher H Straatman K, Flynn H, Skehel M, Hirota T, et al: Differential control of Eg5-dependent centrosome separation by Plk1 and Cdk1. EMBO J 30: 2233-2245, 2011.

37. Wang G, Gao X, Huang Y, Yao Z, Shi Q and Wu M: Nucleophosmin/B23 inhibits Eg5-mediated microtubule depolymerization by inactivating its ATPase activity. J Biol Chem 285: 19060-19067, 2010.

38. Cochran JC, Sontag CA, Maliga Z, Kapoor TM, Correia JJ and Gilbert SP: Mechanistic analysis of the mitotic kinesin Eg5. J Biol Chem 279: 38861-38870, 2004.

39. Rosenfeld SS, Xing J, Jefferson GM and King PH: Docking and rolling, a model of how the mitotic motor Eg5 works. J Biol Chem 280: 35684-35695, 2005.

40. Martens-de Kemp SR, Nagel R, Stigter-van Walsum M, van der Meulen IH, van Beusechem VW, Braakhuis BJ and Brakenhoff RH: Functional genetic screens identify genes essential for tumor cell survival in head and neck and lung cancer. Clin Cancer Res 19: 1994-2003, 2013.
41. Marra E, Palombo F, Ciliberto G and Aurisicchio L: Kinesin spindle protein SiRNA slows tumor progression. J Cell Physiol 228: 58-64, 2013

42. Valensin S, Ghiron C, Lamanna C, Kremer A, Rossi M, Ferruzzi P, Nievo M and Bakker A: KIF11 inhibition for glioblastoma treatment: Reason to hope or a struggle with the brain? BMC Cancer 9: 196, 2009.

43. Tao W, South VJ, Diehl RE, Davide JP, Sepp-Lorenzino L, Fraley ME, Arrington KL and Lobell RB: An inhibitor of the kinesin spindle protein activates the intrinsic apoptotic pathway independently of p53 and de novo protein synthesis. Mol Cell Biol 27: 689-698, 2007. 